\title{
Abordagens cognitivistas na aquisição da língua escrita: revisitando 0 mapa do pezinho
}

\section{Cognitivist approaches in written language acquisition: revisiting 0 mapa do pezinho}

\section{Enfoques cognitivos en la adquisición del lenguaje escrito: revisando El mapa del pie pequeño}

\author{
iD (9) Leosmar Aparecido da Silva \\ Universidade Federal De Goiás, (UFG), Goiânia, Goiás Brasil. \\ E-mail: silva515@ufg.br \\ iD Mirian Santos de Cerqueira \\ Universidade Federal De Goiás, (UFG), Goiânia, Goiás, Brasil. \\ E-mail: mirian_cerqueira@ufg.br \\ iD 9 André Luiz Rauber \\ Universidade Federal De Mato Grosso (UFMT), Cuiabá, Mato Grosso, Brasil. \\ E-mail: andrerauber1@gmail.com
}

Resumo: Este estudo tem como objetivo revisitar, teórica e metodologicamente, o artigo intitulado "Aquisição da escrita: a construção textual em O mapa do pezinho", de Rauber (2008). Para isso, toma como ponto fundamental as abordagens cognitivistas para o estudo da aquisição da língua escrita, tanto numa perspectiva baseada no uso (funcionalista) quanto noutra de viés mentalista (gerativista). A metodologia utilizada para a realização deste trabalho concentra-se na análise qualitativa de um texto produzido por uma criança em idade escolar. Os resultados mostraram que, independentemente das divergências quanto ao processo de desenvolvimento da linguagem escrita, as ciências cognitivas 
ancoradas no gerativismo e no funcionalismo têm muito a contribuir para os estudos sobre a aprendizagem da escrita.

Palavras-chave: Cognição. Linguagem. Desenvolvimento. Língua escrita.

Abstract: This paper is a theoretical and methodological review of the article "Acquisition of writing: the textual construction in O mapa do pezinho", by Rauber (2008). It adopts as fundamental point of view the cognitivist studies about written language learning: on the one hand an approach based on linguistic uses (functionalist); and on the other hand a mentalist framework (generativist). The methodology used in this study is the qualitative analysis of a text elaborated by a schoolchild. The results show us that, regardless of the divergences related to the development process of written language, cognitive sciences represented in generativism and functionalism have a meaningful contribution to the studies on the learning writing.

Keywords: Cognition. Language. Development. Written language.

Resumen: El objetivo de este estudio es revisar, teórica y metodológicamente, el artículo titulado “Adquisición del lenguaje escrito: la construcción textual en O mapa do pezinho", de Rauber (2008). Para eso, se toma como punto fundamental los enfoques cognitivos para el estudio de la adquisición del lenguaje escrito, tanto en una perspectiva basada en el uso (funcionalista) como en otra de sesgo mentalista (generativista). La metodología utilizada para realizar este trabajo se centra en el análisis cualitativo de un texto elaborado por un niño en edad escolar. Los resultados mostraron que, independientemente de las divergencias en cuanto al proceso de desarrollo del lenguaje escrito, las ciencias cognitivas ancladas en el generativismo y el funcionalismo tienen mucho que aportar a los estudios sobre el aprendizaje de la escritura.

Palabras clave: cognición. Idioma. Desarrollo. Lengua escrita.

Submetido em 28 de fevereiro de 2021.

Aceito em 02 de julho de 2021.

Publicado em 06 de janeiro de 2022. 


\section{Considerações iniciais}

A aquisição da língua escrita tem sido objeto de diferentes abordagens teórico-metodológicas há quase uma centena de anos, cada uma atendendo a objetivos distintos, uma vez que representam concepções de língua, linguagem e escrita distintas (BRAGGIO, 1995). É natural haver sempre "uma" perspectiva sobre o objeto científico investigado, conforme ocorre com as ilações sobre a aquisição da língua oral e o desenvolvimento da língua escrita, formuladas, por exemplo, por Piaget (2000), Skinner (1957) e Vigotsky (1998), pesquisadores renomados, cujas descobertas influenciaram e influenciam os estudos sobre como os seres humanos adquirem ou aprendem uma língua.

Muitos "fenômenos" acabam não recebendo a atenção necessária, o que termina por trazer uma visão parcial do tema abordado, quando pensamos na transposição de tais estudos para o campo do ensino da língua materna. Surgiu, assim, o nosso interesse em ampliar o escopo de pesquisa sobre o tema aquisição da língua escrita, de modo a considerar duas diferentes abordagens teóricas para o mesmo tema. Nosso estudo resume-se em verificar como duas correntes teóricas tão distintas como o funcionalismo e o gerativismo podem contribuir para o estudo do tema da aquisição da escrita, e como isso pode reverberar, em alguma medida, para o ensino da escrita em sala de aula.

Defendemos uma análise que contemple visões teóricas distintas, no entanto, capazes de compreender o texto como o resultado de um processamento de ordem cognitiva, pragmática e mentalista. Esperamos, assim, contribuir enormemente para a compreensão do fenômeno investigado e ampliar o trabalho do professor em sala de aula de Língua Portuguesa na Educação Básica (KENEDY, 2013; AVELAR, 2017).

Para isso, elencamos três questões a serem desenvolvidas neste estudo: 1) De que forma abordagens teóricas distintas compreendem o desenvolvimento da escrita pela criança em idade 
Abordagens cognitivistas na aquisição da língua escrita: revisitando O mapa do pezinho Leosmar Aparecido da Silva • Mirian Santos de Cerqueira • André Luiz Rauber

escolar?; 2) Como os fenômenos linguísticos, evidenciados numa produção escrita, podem ser interpretados sob princípios teóricos distintos, mas objetivos complementares?; 3) Sobre a análise feita por Rauber (2008) de um corpus escrito em contexto escolar em 2003, quais os aspectos suscetíveis à atualização, de acordo com os critérios apontados neste estudo?

Para responder às questões levantadas, organizamos este artigo em três seções. Na primeira, apresentamos as duas principais abordagens teóricas para o estudo da aquisição da escrita: abordagem gerativista e abordagem funcionalista, cujo ponto de contato concentra-se no critério cognitivo presente em ambas. $\mathrm{Na}$ segunda, descrevemos a metodologia empregada no presente estudo. Na terceira, discutimos os dados e atualizamos a análise do texto "Aquisição da escrita: a construção textual em O mapa do pezinho" (RAUBER, 2008), objeto de estudo no curso sobre aquisição da linguagem, lecionado pela Professora Doutora Sílvia Braggio, no programa de Pós-Graduação em Letras e Linguística da Universidade Federal de Goiás, em 2003. Finalmente, na quarta e última parte, apresentamos algumas considerações resultantes deste estudo, que tem como uma de suas motivações render homenagens à contribuição pedagógica e científica da Professora e Pesquisadora Sílvia Braggio, cuja produção bibliográfica e discussões em aula contribuíram para a divulgação da perspectiva sociocognitiva da aprendizagem da língua escrita.

\section{As abordagens formal e funcional sobre a aquisição da linguagem}

A confluência de duas correntes de estudo da linguagem tem um impacto significativo sobre os conceitos teóricos que sustentam as discussões e considerações deste estudo. A compreensão de como ocorre a aquisição da linguagem é percebida de forma distinta por gerativistas e funcionalistas. Enquanto o paradigma gerativista compreende a aquisição da linguagem como um resul- 
Abordagens cognitivistas na aquisição da língua escrita: revisitando O mapa do pezinho Leosmar Aparecido da Silva • Mirian Santos de Cerqueira • André Luiz Rauber

tado evolutivo genético, portanto, inato (CHOMSKY, 1994; KATO, 2005), os seguidores do modelo funcionalista defendem que a aquisição da linguagem é o resultado do desenvolvimento da interação comunicativa entre a criança e o seu ambiente (DIK, 1997; TOMASELLO, 1999, 2003).

Neste artigo, tais dissensos teóricos são positivos, pois ampliam a possibilidade analítica de um fenômeno tão complexo que é o desenvolvimento da escrita alfabética. Além disso, quando considerado o domínio cognitivo que subjaz a aprendizagem de um código escrito simbólico, é possível reconhecer as contribuições das visões inatistas e empiristas para a compreensão da complexidade do princípio alfabético (SILVA, 2004). Assim, resta-nos esclarecer que, como a corrente gerativista admite o termo "aquisição" unicamente para designar a aquisição da língua oral, optamos pelo emprego das expressões "desenvolvimento" e "aprendizagem" para nomear o processo inerente à língua escrita e o seu correlato cognitivo (BRAGGIO, 1992, 1999).

\subsection{As contribuições da abordagem gerativa}

Como é sabido, o Programa de Investigação da Gramática Gerativa, cujo fundador é Noam Chomsky, toma como questões centrais de seu interesse: 1) O que é o conhecimento linguístico; 2) Como esse conhecimento é adquirido; 3) Como esse conhecimento é colocado em uso (CHOMSKY, 1994). Para responder às questões apresentadas, Chomsky (1994) parte da hipótese de que os seres humanos são possuidores de uma capacidade inata de linguagem, alocada na mente/cérebro, o que ficou conhecido como Faculdade de Linguagem. Para o linguista, é graças a essa capacidade que nos distinguimos das demais espécies. É com esse pensamento que Chomsky (1957) inaugura uma revolução no campo das ciências cognitivas, ao contestar a ideia de que a linguagem seria uma forma de comportamento, aprendida por meio de es- 
Abordagens cognitivistas na aquisição da língua escrita: revisitando 0 mapa do pezinho Leosmar Aparecido da Silva • Mirian Santos de Cerqueira • André Luiz Rauber

tímulos, conforme propôs Skinner (1957) em sua clássica obra 0 comportamento verbal.

Para estabelecer as bases do Gerativismo, Chomsky (1994) irá defender a hipótese inatista para a aquisição da linguagem. Segundo ele, a aquisição ocorre na interação entre as propriedades da Gramática Universal e os dados linguísticos primários (input), aos quais a criança tem acesso nesse processo. Essa Gramática Universal (GU) é considerada o Estágio inicial da Faculdade de Linguagem, sendo formada por Princípios e Parâmetros. Aqueles são propriedades universais e invariáveis, devendo ocorrer em todas as línguas naturais, ao passo que estes, os Parâmetros, são propriedades variáveis de uma língua para outra.

Um exemplo de Princípio é o fato de que todas as línguas naturais projetam na sintaxe uma posição estrutural para o sujeito das sentenças (Princípio de Projeção Estendido). Como exemplo de Parâmetro, temos o fato linguístico de que nem todas as línguas preenchem foneticamente a posição de sujeito, conforme podemos constatar nos exemplos em (1) e (2):

1. Vamos à festa.

2. We go to the party.

Em (2), temos a exemplificação do inglês, língua que preenche obrigatoriamente a posição de sujeito sentencial, ou seja, que marca negativamente o valor do Parâmetro do Sujeito Nulo'. Diferentemente, em (1), verificamos a possibilidade de o sujeito ser ou não preenchido foneticamente, como ocorre em Português Europeu, por exemplo. Nesse caso, temos uma língua de Sujeito Nulo prototípica. A variabilidade atestada nos exemplos apresentados confirma a hipótese chomskyana de que a tarefa da criança no processo de aquisição é marcar os valores dos parâmetros, os

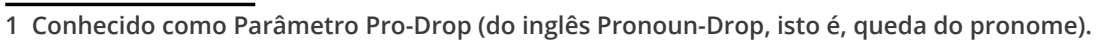


Abordagens cognitivistas na aquisição da língua escrita: revisitando O mapa do pezinho Leosmar Aparecido da Silva • Mirian Santos de Cerqueira • André Luiz Rauber

quais já estão previstos na GU. Essa marcação só é possível porque a criança tem acesso aos dados linguísticos que lhe circundam.

A respeito do papel dos estímulos no processo de aquisição, Chomsky (1994) irá defender a hipótese da "Pobreza de Estímulos", pois, segundo ele, os dados linguísticos a que a criança tem acesso são fragmentados. Isso justificaria a aposta que o autor faz na capacidade inata dos falantes. Atrelada a essa questão, no âmbito da aquisição, interessa ao gerativismo as seguintes questões: como sabemos tanto a partir de tão poucas evidências? Como sabemos tão pouco sobre a linguagem se já há investigações sobre esse tema há tanto tempo? A primeira questão ficou conhecida como "Problema de Platão", uma vez que parte da premissa de que o conhecimento linguístico é radicado na mente. Essa questão se alinha à "Pobreza de Estímulos"2, pois encontra nas propriedades da Faculdade da Linguagem a explicação para o processo de aquisição; a segunda questão ficou conhecida como "Problema de Orwell"3, pois se refere ao modo como lidamos com o mundo observável, ou seja, com as evidências e o porquê de não conseguirmos enxergar aquilo que é óbvio do ponto de vista racional.

Nesse paradigma teórico, Chomsky (1957) irá distinguir os conceitos de Língua-I e Língua-E. A primeira, de caráter inato, interno, individual e intensional ${ }^{4}$, está relacionada, portanto, ao plano da competência do falante; diferentemente, a segunda apresenta caráter social, externalizado, relacionando-se ao plano do desempenho linguístico do falante.

Para melhor compreendermos como se dá a aprendizagem da escrita em contexto escolar, vamos nos valer, no âmbito gerativista, da proposta apresentada por Kato (2005) acerca da variedade linguística que se aprende na escola, ou seja, focalizaremos

\footnotetext{
2 Lopes (1999, p. 53) explica o problema de Platão: “[...] Problema de Platão: as pessoas vêm a adquirir um conhecimento maior do que aquele que a experiência poderia proporcionar. A diferença entre ambos - conhecimento atingido e experiência - ficou conhecida, na literatura, como o argumento da 'pobreza de estímulo'. A dedução é simples: quanto mais inadequada a experiência, tanto mais estruturado o conhecimento inato a ser previsto".

3 “O estudo do problema de Orwell é, pois, basicamente uma questão de reunião de evidências e exemplos para ilustrar aquilo que seria óbvio para um observador racional, mesmo que numa análise superficial, para se chegar à conclusão de que o poder e o privilégio funcionam tal como qualquer mente racional deveria esperar que funcionassem e para revelar os mecanismos que operam para produzir os resultados que observamos" (CHOMSKY, 1994, p. 18).

4 Intensional com " $S$ ", pois refere-se à capacidade que uma unidade linguística tem de se combinar infinitamente. Nesse sentido, o que interessa a Chomsky é essa capacidade de combinação de itens finitos de maneira infinita. A partir de um número limitado de regras, os falantes de uma língua natural podem produzir frases infinitamente.
} 
Abordagens cognitivistas na aquisição da língua escrita: revisitando 0 mapa do pezinho Leosmar Aparecido da Silva • Mirian Santos de Cerqueira • André Luiz Rauber

o conceito de "Gramática do Letrado" proposto pela autora. Na medida do possível, buscaremos estabelecer uma "aproximação" desse conceito com os dados de escrita analisados no presente estudo.

No texto clássico No mundo da escrita, Kato (1986) aborda, no âmbito da perspectiva psicolinguística, os processos de aprendizagem por que passam os aprendizes no campo da leitura e da escrita, propondo, assim, que se reflita sobre tal questão a partir de uma teoria da aprendizagem da linguagem escrita.

Conforme Félix (1987 apud Kato, 1999, p. 22), “o que se aprende na escola, ao contrário do que se aprende como primeira língua, pode envolver processos de aprendizagem que ativam não a GU, mas um mecanismo geral piagetiano de resolução de problema".

Em Kato (2005), a autora aprofunda a investigação em torno daquilo que ficará conhecido como "Gramática do letrado", discorrendo sobre a natureza do processo de aprendizagem da escrita por falantes brasileiros em contexto escolar. Tal processo estaria atrelado ao tipo de acesso que os falantes letrados teriam em relação aos conhecimentos da Gramática Universal. Para isso, ela adota as noções de "Gramática Nuclear" e "Periferia marcada", conforme postulado por Chomsky (1994). Para a autora,

no Brasil, ao contrário do que ocorre em Portugal, a gramática da fala e a 'gramática' da escrita apresentam uma distância de tal ordem que a aquisição desta pela criança pode ter a natureza da aprendizagem de uma segunda língua (KATO, 2005, p. 131).

Nessa perspectiva, ao iniciar o processo de aquisição da escrita no âmbito escolar, a criança se vê diante de dados linguísticos que não correspondem ao conhecimento internalizado de sua língua materna, ou, em termos chomskyanos, da sua língua-I. Isso significa que a criança será submetida a um conjunto de regras e metalinguagem que farão parte de um repertório "estranho" à sua natureza linguística. Um caso típico dessa situação é a aprendiza- 
Abordagens cognitivistas na aquisição da língua escrita: revisitando 0 mapa do pezinho Leosmar Aparecido da Silva • Mirian Santos de Cerqueira • André Luiz Rauber

gem de clíticos pronominais em posição de ênclise pela criança brasileira (CERQUEIRA; SILVA, 2021). Ao contrário do que ocorre com a criança portuguesa, que adquire a ênclise naturalmente em seu processo de aquisição, a criança brasileira só tem acesso a esse conhecimento por meio de instrução formal na escola, o que, na maioria das vezes, se realiza por meio de ensino tradicional com ênfase em exercícios gramaticais de repetição de padrão morfossintático, sem qualquer reflexão "epilinguística" sobre os usos da língua.

\subsection{As contribuições da abordagem funcional}

Partindo da consideração de Braggio (1992, p. 70), baseada em Goodman (1984), de que "o modo como a linguagem escrita é compreendida não é diferente do modo como a linguagem oral é compreendida", apresentamos, nesta seção, as contribuições dos Modelos Baseados no Uso (LANGACKER, 1987; BYBEE, 2010; TOMASELLO, 1999, 2003, e outros) para a compreensão da aquisição da linguagem e, posteriormente, a aplicação de alguns princípios à análise do texto $O$ mapa do pezinho.

Os Modelos Baseados no Uso, que possuem uma concepção cognitivo-funcional da linguagem, defendem a ideia de que $o$ uso das expressões da língua é o principal elemento motivador da construção do sistema linguístico. Defendem ainda que a linguagem é essencialmente simbólica, uma vez que cada unidade da língua dispõe do pareamento forma-função. Para cada forma, há uma ou mais funções correspondentes. Com isso, de acordo com Langacker (2013), léxico e gramática formam uma gradação baseada unicamente na montagem de estruturas simbólicas. Diferentemente do gerativismo, essa abordagem apresenta evidências de que o conhecimento linguístico humano está integrado ao restante da cognição humana (CROFT; CRUSE, 2004; TOMASELLO, 2003). Assim, a linguagem não teria um módulo específico na men-

$\overline{50}$ uso do termo "epilinguístico", neste artigo, segue os pressupostos de Franchi (1987) e Geraldi (1997). 
te humana, mas atuaria em conjunto com a percepção, a atenção, a memória, a associação, a imaginação, o pensamento etc. A linguagem, então, só seria adquirida porque outros componentes cognitivos atuariam em conjunto para o desenvolvimento do componente linguístico.

Bybee (2010) considera que olhar para os processos gerais que criam a estrutura linguística tem a vantagem de se estreitar a busca por processos específicos da língua e de se situar a linguagem no contexto mais amplo do comportamento humano. A autora apresenta, então, cinco processos cognitivos de domínio geral que contribuem para o desenvolvimento de processos específicos da linguagem: categorização, chunking, memória rica, analogia e associação transmodal.

A “categorização", segundo Bybee (2010), diz respeito ao agrupamento de unidades simbólicas a um grupo específico, dada a similaridade dos componentes. A cognição geral tende a colocar no grupo das frutas elementos que originam de flor, possuem polpa e semente, são comestíveis. Similarmente, as unidades linguísticas são "organizadas" na mente em categorias, tais como "nome" e "verbo". O chunking é o processo pelo qual algumas unidades se juntam para formar unidades maiores. Na cognição geral, há pertinência na junção de chave e carro. Na linguagem, há pertinência em juntar com+migo, formando "comigo". A "memória rica" diz respeito à estocagem na mente de detalhes da experiência, sejam eles linguísticos ou não. Pode-se estocar detalhes fonéticos, contextos de uso, significados e inferências.

A "analogia", por sua vez, trata da estrutura relacional que permite a criação de enunciados novos a partir de enunciados previamente dados. Cenas, formatos, cores são alguns estímulos visuais que permitem, por exemplo, fazer associação por semelhança entre um pássaro e um avião; ou entre a "onda do mar" com a "onda sonora", com a "onda do cabelo", com a "onda do fumo", com a "onda revolucionária". A "associação transmodal" permite ligar significado e forma. Um adulto associa o horário de 8h30 da manhã à entrega das correspondências pelo correio. Em termos linguís- 
ticos, pode associar a ideia de "corrente", "tendência", sistema", "doutrina" ao sufixo "-ismo". Todos esses processos pelos quais os seres humanos apre(e)ndem contribuem igualmente para apre(e) nderem a linguagem.

Para Tomasello (1999), a percepção de intenções e a identificação de padrões são outros dois processos cognitivos gerais que atuam na aquisição da linguagem. A percepção de intenções inclui as habilidades de: 1) compartilhar com outras pessoas atenção sobre objetos e eventos; 2) seguir a atenção dos outros para objetos distantes, por meio do gesto de apontar; 3) aprender culturalmente as ações intencionais dos outros (TOMASELLO, 1999, p. 3). Acompanhar com o olhar para os mesmos lugares onde os adultos olham, agir sobre os objetos da mesma forma que os adultos são exemplos de percepção das intenções.

Já a identificação de padrões inclui as habilidades de: 1) relacionar objetos e eventos similares, formando categorias perceptuais e conceptuais para tais objetos e eventos; 2) formar esquemas sensório-motores, como engatinhar, andar etc; 3) identificar sequências; 4) criar analogias/similaridades entre duas ou mais categorias (TOMASELLO, 1999, p. 4). Um exemplo da identificação de padrões é a produção de combinação de palavras com uma fórmula em que há um evento ou estado que é constante e um participante que é variável (TOMASELLO, 1999). As crianças percebem que os adultos dizem coisas como "mais suco", "mais leite", "mais bolachas", "mais uvas". Como resultado dessa identificação de padrões, são capazes de inferir o esquema "Mais X". A criança aprende, então, que pode usar tal esquema para incluir outros elementos no campo do item variável. O mesmo processo ocorre em construções verbais transitivas ou não, por exemplo, como em " $X$ chutar Y"; "X dar Y para Z"; "X cair". Para Tomasello (1999, p. 134), ao aprender o verbo "dar", por exemplo, a criança aprende também que há aquele que dá, a coisa dada e a pessoa para a qual se dá. O mesmo ocorre com as palavras "fora" e "de", em que há uma relação com outras entidades ou locativos. 
Tomasello (1999) enumera basicamente quatro processos pelos quais as crianças passam no desenvolvimento de sua linguagem: as holófrases, as construções com ilhas verbais, as construções abstratas e as narrativas. Para o autor, as "holófrases" são manifestações linguísticas da criança por meio de uma única palavra que expressa o todo de seus desejos ou intenções. A criança pode dizer apenas "pão" para expressar, por exemplo, "Eu quero comer pão". Acrescenta, ainda, que solicitações e apontamento de coisas são as primeiras manifestações verbais das crianças, o que coloca em destaque a aquisição de construções imperativas e afirmativas antes das interrogativas. As "construções com ilhas verbais" (TOMASELLO, 1999) são aquelas em que se verifica um elemento linguístico constante e outros variáveis, como em "Eu desenhei X para Y". As "construções abstratas" são esquemas cognitivos construídos lentamente como padrões extraídos de construções com ilhas verbais individuais, resultando em um protótipo como centro e exemplares periféricos. Para o autor, em inglês, sentenças do tipo "ele chutou a bola" permitem ilhas verbais do tipo ___chutar"___ que resulta no esquema abstrato " $X$ chutar $\mathrm{Y}^{\prime \prime}$ de uma sentença transitiva.

Por fim, em relação às "narrativas", segundo Tomasello (1999, p. 142), as crianças cotidianamente experienciam, no discurso, construções linguísticas complexas em que vários eventos simples ou estados de coisas são encadeados de modo conjunto numa narrativa, tipicamente com um ou mais participantes constantes, ligados por meio de eventos e relações causais intencionais, dando à sequência um tipo de coerência racional que distingue a narrativa de uma cadeia de eventos aleatórios. As crianças não apenas aprendem a fazer isso - ainda que não seja bem compreendido como conseguem aprender a controlar os mesmos participantes por meio de múltiplos eventos e papéis enquanto conectam os eventos e papéis, por meio de elementos coesivos.

Para Tomasello (1999), a interação entre palavras individuais concretas e construções linguísticas abstratas cria novas e poderosas possibilidades para o desenvolvimento linguístico derivacio- 
Abordagens cognitivistas na aquisição da língua escrita: revisitando O mapa do pezinho Leosmar Aparecido da Silva • Mirian Santos de Cerqueira • André Luiz Rauber

nal, analógico e metafórico. É o caso, por exemplo, de sentenças do tipo "azul é minha cor favorita" e "esquiar é engraçado", em que propriedades (azul) e atividades (esquiar) são vistas metaforicamente como objetos.

Em síntese, o modo de desenvolvimento linguístico da criança, conforme a perspectiva das Teorias Baseadas no Uso, é possível, segundo Bezerra e Souza (2013),

a partir do momento em que ela [a criança], engajada em quadros ou cenas de atenção conjunta - microespaços culturais e linguísticos, começa a entender que existe uma intenção motivando a produção linguística do adulto e que ela pode valerse deste mesmo instrumento linguístico quando possuir uma intenção semelhante, conseguindo alcançar uma competência linguística por meio de processos imitativos e analógicos baseados em interações contínuas com adultos linguisticamente competentes (BEZERRA; SOUZA, 2013, p. 30).

Importante esclarecer que os processos imitativos a que fazem referência Tomasello (1999, 2003) e Bezerra e Souza (2013) não são mecânicos, já que há "a reflexão da intenção do outro" (BEZERRA; SOUZA, 2013, p. 27) e a consequente percepção da possibilidade de utilização da mesma estratégia de modo criativo.

Apesar de a abordagem gerativa e a abordagem funcional, baseada no uso, divergirem quanto à modularidade (linguagem como sistema autônomo) ou não modularidade (linguagem como sistema integrado às demais faculdades da mente) da cognição humana, "ambas as perspectivas assumem a linguagem como uma habilidade exclusiva da espécie humana e a predisposição inata para a sua aquisição", conforme mostram Bezerra e Souza (2013, p. 27). Tais considerações constituem a gênese deste trabalho.

Uma aproximação entre a perspectiva cognitivo-funcional dos Modelos Baseados no Uso e as considerações da sociopsicolinguística aplicadas à leitura e à escrita, descritas por Braggio (1992), 
Abordagens cognitivistas na aquisição da língua escrita: revisitando O mapa do pezinho Leosmar Aparecido da Silva • Mirian Santos de Cerqueira • André Luiz Rauber

revela-nos que a dimensão sócio-histórica-cultural subjaz a aquisição da linguagem oral, a compreensão e a escrita. Para Braggio (1992), o contexto da linguagem opera sobre o processamento cognitivo das manifestações oral e escrita da língua. É o contexto que "direciona a própria utilização das estratégias cognitivas para processá-la e, que, finalmente, desemboca na performance do leitor/escritor" (BRAGGIO, 1992, p. 76). Para Braggio (1999), a visão sociopsicolinguística tem uma formulação cíclica em que o contexto da linguagem modifica os esquemas mentais, os quais direcionam a utilização de estratégias para a produção de leitura e escrita. Tais estratégias, por sua vez, mapeiam o contexto de linguagem. Essa organização cíclica é representada pela seguinte figura, reproduzida de Braggio (1992, p. 77):

Figura 1 - Representação do modelo sociopsicolinguístico

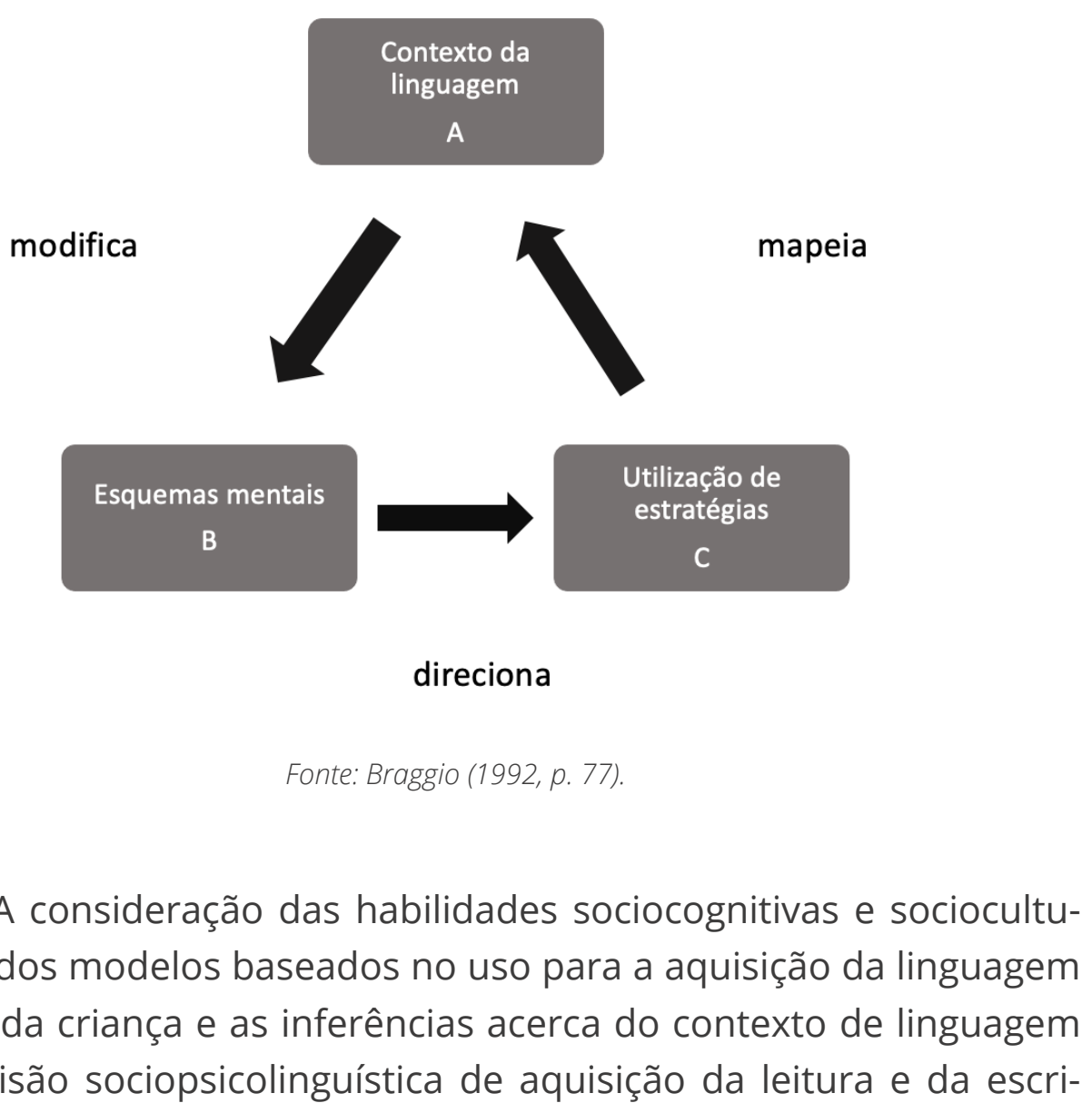


Abordagens cognitivistas na aquisição da língua escrita: revisitando 0 mapa do pezinho Leosmar Aparecido da Silva • Mirian Santos de Cerqueira • André Luiz Rauber

ta podem contribuir positivamente para o ensino/aprendizagem de tais competências no contexto escolar. Uma proposta alternativa àquelas produções pouco autorais, como "Vovô amava a vovó. I Vovô tocava viola. I Vovó ouvia o vovô. / Viva a vovó e o vovô." (BRAGGIO, 1992, p. 77, grifo do autor).

\section{Metodologia}

Levando em consideração que o presente artigo tem como principal objetivo revisitar teórica e metodologicamente o trabaIho de Rauber (2008) acerca da aquisição da língua escrita e tomar como pressupostos teóricos a abordagem gerativa e a cognitivo-funcional centrada no uso, este estudo circunscreve-se à análise qualitativa.

O corpus de análise corresponde à produção textual escrita de uma aluna do $1^{\circ}$ Ciclo da Educação Básica (doravante CEB). Analisamos, portanto, o mesmo corpus examinado por Rauber (2008).

Em relação à análise, inicialmente reproduzimos a materialidade do texto produzido pela criança do $1^{\circ}$ Ciclo e a sua transcrição. Posteriormente, dividimos a análise em duas subseções específicas. A primeira analisa o texto de acordo com os postulados gerativistas. A segunda analisa o mesmo texto conforme os postulados cognitivo-funcionais dos estudos centrados no uso. Assim, alguns aspectos teóricos expostos na seção 1 deste artigo são retomados na seção de análise e discussão dos dados.

\section{Análise e discussão dos dados}

O texto que constitui o corpus desta análise intitula-se $O$ mapa do pezinho e foi produzido por uma aluna do que hoje corresponde ao $1{ }^{\circ} \mathrm{Ciclo}$ do Ensino Básico ( $\left.{ }^{\circ} \mathrm{CEB}\right)$, ou seja, do primeiro ao quarto anos do Ensino Fundamental. Caracteriza-se, por isso, 
Abordagens cognitivistas na aquisição da língua escrita: revisitando O mapa do pezinho Leosmar Aparecido da Silva • Mirian Santos de Cerqueira • André Luiz Rauber

como uma produção escrita em contexto escolar. Tal produção, reproduzida a seguir, foi resultante de um processo que se iniciou com as orientações da professora da turma acerca do gênero textual em foco.

Figura 2 - Reprodução do texto escolar

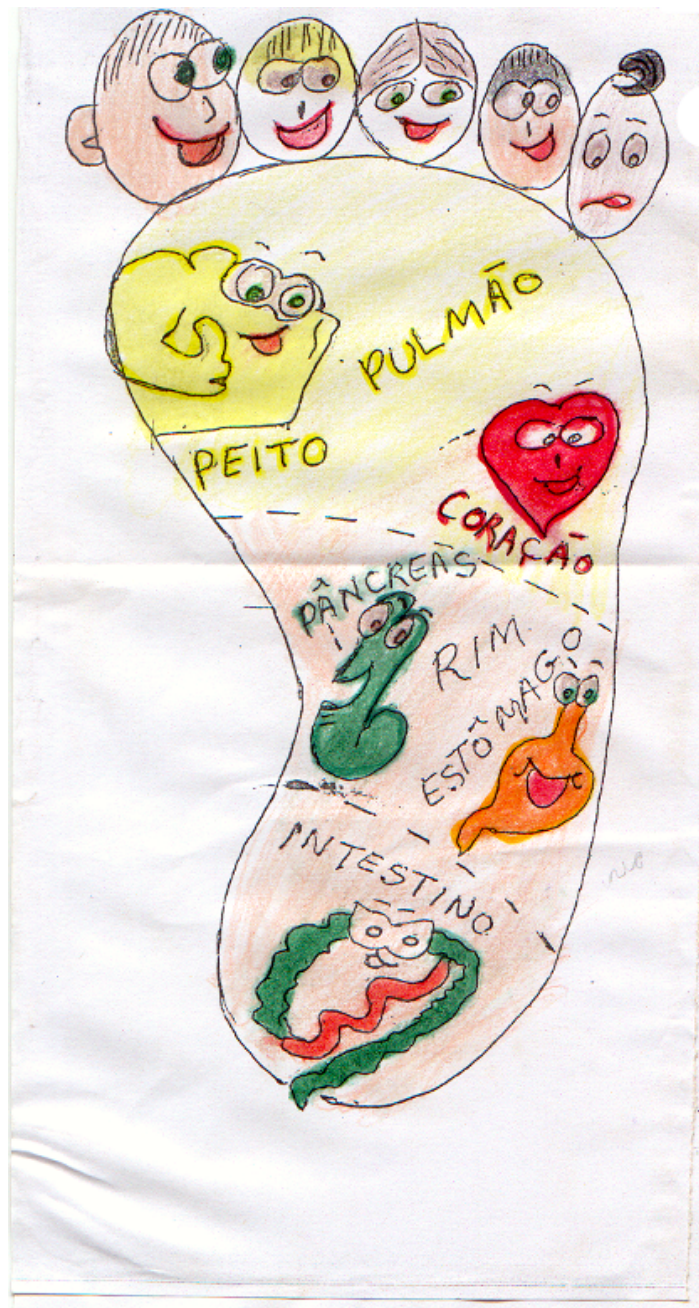

- Omapa do pezinho

OMapa do pezinho

(1) pezinho e muinto delicacado. voce laz massage no seu pé. Eu faco no meu vocè massagria o seu pezinho também vai esta" massage ando $\theta$ orgä, $\theta$ intestino, Q estoma go voci massagea. ndo muintas coisas você vai ficar ulachado lo sell pezenho vai ficar lue o pezinho do bîlue ele vai ficar buncando com a pezunho o dia tra 
Abordagens cognitivistas na aquisição da língua escrita: revisitando 0 mapa do pezinho Leosmar Aparecido da Silva • Mirian Santos de Cerqueira • André Luiz Rauber

\title{
Transcrição literal do texto
}

\author{
O mapa do pezinho \\ 10 pezinho e muito delica \\ 2 ado. você faz massage no \\ 3 seu pé. Eu faço No meu \\ 4 você massageia o seu pezinho \\ 5 também vai está massage \\ 6 ando o órgão, o intestino, \\ 7 o estômago. você massagea \\ 8 ndo muintas coisas \\ 9 você vai ficar relachado \\ 10 e o seu pezinho vai ficar \\ 11 leve o pezinho do bêbê \\ 12 ele vai ficar brincando \\ 13 com o pezinho o dia todo
}

Várias são as perspectivas das quais poderíamos lançar mão para analisar esta produção escrita. Pelas razões indicadas no início deste artigo, ousamos contrapor duas abordagens epistemologicamente distintas, as quais, no entanto, compartilham o critério cognitivo, seja no processamento mental/cerebral, como o faz o Gerativismo, seja no uso, conforme a perspectiva cognitivo-funcional.

\subsection{Análise do texto sob a perspectiva gerativa}


Para início de análise, um aspecto que nos chama a atenção no texto em estudo, O mapa do pezinho, é o fato de as posições sintáticas de sujeito apresentarem-se todas preenchidas morfofonologicamente, ou seja, o fato de não verificarmos a ocorrência de sujeitos nulos, o que, de alguma forma, nos leva a concordar com os estudos gerativistas e também variacionistas ao defenderem que o Português Brasileiro está caminhando para se tornar uma língua de sujeito preenchido. Nesse sentido, conforme defende Magalhães (2000), seguindo os postulados de Kato (2005), a criança brasileira aprenderia o sujeito nulo na escola. Para a autora,

com relação à escolaridade foi possível perceber que mesmo com a imposição de gramática normativa (doravante GN), que requer o uso de sujeitos pronominais nulos na escrita sempre que possível, as séries iniciais usam o sujeito preenchido, opção já licenciada pela gramática internalizada (GI). Essa opção só começa a mudar no final do $1^{\circ}$ grau (MAGALHÃES, 2000, p. 41).

Essa constatação feita por Magalhães (2000) nos leva a considerar as diferenças entre a gramática do adulto e a gramática da criança como fundamentais para que se compreenda, do ponto de vista gerativista, o papel da Gramática Universal frente ao processo de aquisição de uma língua particular. Nesse sentido, saber qual a tarefa da criança nesse processo faz toda a diferença quando pensamos do ponto de vista da aprendizagem formal da língua escrita, ou seja, saber que a escola terá de respeitar o processo maturacional da criança e todo o conhecimento internalizado sobre sua língua-I, ao propor, por exemplo, atividades epilinguísticas e metalinguísticas que levem em conta o processo natural de aquisição da criança. Isso significa, em termos didáticos, requerer da criança o conhecimento que ela é capaz de demonstrar nas etapas apropriadas para isso, sem desconsiderar o conhecimento gramatical de que ela já dispõe quando inicia no "mundo da escrita".

A exemplo disso, verificamos no texto, nas linhas de 11 a 13, uma construção de tópico-comentário ("o pezinho do bêbê ele 
vai ficar brincando com o pezinho o dia todo"), construção típica da fala no Português Brasileiro, conforme observou Eunice Pontes (1987). Segundo a autora, o Português Brasileiro está deixando de ser uma língua de sujeito-verbo para se tornar uma língua de tópico-comentário. Isso demonstra, de certo modo, que a criança, no processo de aprendizagem da escrita, vai utilizar os dados do seu vernáculo num primeiro momento, ou seja, da sua gramática internalizada. O que a escola faz em relação a isso, muitas vezes, e sem considerar as especificidades próprias desse processo, é tentar reestruturar a sintaxe da criança com vistas à aprendizagem de uma língua que só existe no universo da escrita formal fossilizada, pois remonta, em alguns casos, a construções arcaicas que não fazem parte do Português falado no Brasil.

À revelia do que a escola ensina ou pretende ensinar, não podemos deixar de notar, no texto em análise, a capacidade da criança de combinar itens lexicais em diferentes sintagmas e funções, bem como os conhecimentos sintático-semânticos relacionados a essa operação de concatenação. Esse fato, por si só, já é um dado linguístico importante para corroborar a validação da hipótese inatista da linguagem formulada por Chomsky (1994, e obras posteriores), uma vez que considera toda a criatividade linguística do falante e o fato de que sabemos muito mais do que aquilo que expressamos.

Uma prova disso, por exemplo, pode ser verificada através do conhecimento da criança sobre a operação de omissão de constituintes, conforme apresentado a partir do seguinte trecho: "você faz massagem no seu pé. Eu faço no meu". Há, no segundo período do texto, uma elipse dos constituintes nominais [massagem], complemento do verbo "fazer", e [pé], em posição de núcleo nominal do sintagma [o meu pé], o que aponta para o fato de que a criança possui conhecimento sintático sobre a estruturação dos constituintes e também se utiliza da propriedade da Faculdade de Linguagem denominada de recursividade. Tal propriedade, nesse contexto, se apresenta por meio da produção de orações coordenadas, ao invés de períodos mais complexos de orações encaixa- 
Abordagens cognitivistas na aquisição da língua escrita: revisitando O mapa do pezinho Leosmar Aparecido da Silva • Mirian Santos de Cerqueira • André Luiz Rauber

das, como pode ser verificado ao longo de todo o texto produzido pela criança.

Um outro aspecto que vale a pena pontuar a partir do texto em análise é o uso que a criança faz do pronome "você", ou seja, como pronome pessoal de $2^{a}$ pessoa, contrariamente ao que é ensinado formalmente na escola quando se prescreve o quadro de pronomes pessoais do caso reto, quer seja por meio de livros e manuais didáticos, quer seja por meio de gramáticas normativas. Tal fato leva-nos a, mais uma vez, argumentar em torno da ideia de Kato (2005), segundo a qual a gramática da escola é "fossilizada", ou seja, de natureza periférica, pois se vale de construções encontradas em outras épocas da língua, numa clara evidência de que não acompanha as variações e mudanças que ocorrem na língua falada.

Ainda sobre o pronome "você", uma outra hipótese que podemos aventar acerca de sua presença no texto em questão é a que diz respeito ao fato de a criança se valer de uma estratégia muito utilizada na gramática dos adultos, que é o uso do "você" como índice de indeterminação do sujeito. Ao invés de usar o clítico "se" para essa operação, os falantes optam pelo pronome reto "você", como em "você massageia o seu pé", em substituição à construção "Massageia-se o seu pé".

Esse conhecimento internalizado sobre a língua é algo que, dificilmente, o ensino formal na escola consegue explicar. Essa "ausência" de explicação ou falta de compreensão do que ocorre com a criança no processo de aquisição da língua materna contribui, muitas vezes, no âmbito da aprendizagem formal da escrita, para a prática de exercícios estruturais que desconsideram, em larga medida, a capacidade linguística da criança e sua Faculdade de Linguagem, ou seja, focaliza regras e padrões que não condizem com a complexidade sintática natural que esta já possui ao ingressar à escola. Isso, por sua vez, termina por dificultar o processo de desenvolvimento da escrita da criança e os seus mais diversos níveis de letramento, sem os quais o mundo da escrita se torna 
Abordagens cognitivistas na aquisição da língua escrita: revisitando 0 mapa do pezinho Leosmar Aparecido da Silva • Mirian Santos de Cerqueira • André Luiz Rauber

inoperante e inacessível, colocando em jogo, por assim dizer, o seu direito da criança à cidadania.

\subsection{Análise do texto sob a perspectiva dos modelos baseados no uso}

O texto $O$ mapa do pezinho tem uma composição multimodal, uma vez que apresenta um desenho do lado esquerdo e o texto escrito do lado direito. O desenho representa, na visão sociocognitiva, e também na visão de Vygotsky (1988), parte do processo do desenvolvimento da linguagem. $O$ desenho é um modo de expressão de conhecimentos armazenados na memória rica de que fala Bybee (2010). Essa memória é construída, segundo Abreu (2020), desde que nascemos, pelo aprendizado contínuo. Armazenamos na memória de longo termo o conhecimento, por exemplo, de que um cachorro pode andar, correr, pular, latir, abanar o rabo, morder, lamber; de que ele pode ser de guarda ou de companhia; de que não é um animal de montaria como o cavalo.

No texto 0 mapa do pezinho, para a criança, o desenho do pé e, dentro dele, a representação dos órgãos vitais (pulmão, peito, coração, rim, estômago, intestino), foi introduzido pela professora, conforme mencionado por Rauber (2008). Possivelmente decorreu de alguma exposição oral sobre reflexologia ${ }^{6}$. Como atividade de pré ou pós-escrita, foi solicitado que os alunos colorissem o desenho. As cenas vistas e ouvidas ficaram armazenadas na memória e o output foi a produção de linguagem escrita. Essas são evidências de que, para a manifestação da linguagem, fez-se necessária a atuação do processo cognitivo geral da "memória rica". Logo, a linguagem, seja ela falada ou escrita, é possível devido à atuação de outros componentes cognitivos acionados conjuntamente.

O desenho funciona como uma síntese visual do texto escrito e isso conecta, de modo coerente, as linguagens verbal e não verbal. Ao colorir os cabelos, os olhos, o nariz, a boca e a orelha

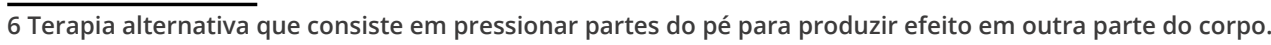


Abordagens cognitivistas na aquisição da língua escrita: revisitando O mapa do pezinho Leosmar Aparecido da Silva • Mirian Santos de Cerqueira • André Luiz Rauber

dos dedos dos pés, a criança tem contato com um dos processos gerais descritos por Bybee (2010), a "analogia". No caso em questão, tem-se a mescla conceptual "dedos do pé" e "ser humano". Os dedos dos pés são concebidos, metafórica e metonimicamente, como seres que têm vida, que são humanos, tal como se observa na reprodução a seguir:

\section{Figura 3 - Recorte dos dedos dos pés do desenho}

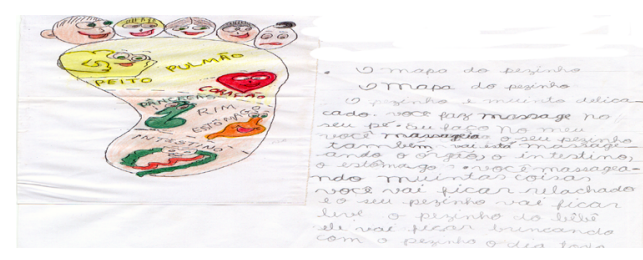

Fonte: Acervo pessoal de André Rauber.

A analogia é metafórica, porque faz-se a transferência de um domínio (dedos) para outro (ser humano). É metonímica, porque considera as relações entre parte (os dedos dos pés) e o todo (o corpo humano). Há, portanto, uma representação metaftonímica ${ }^{7}$ não verbal.

No que diz respeito à organização textual-discursiva do texto, há nele uma sequenciação lógica que, conforme Rauber (2008), garante a coesão interna. A sequenciação pode ser assim sintetizada:

1. caracterização do pé;

2. orientação para a massagem;

3. relação entre a massagem do pé com os órgãos vitais;

4. consequências/vantagens da massagem;

5. exemplificação com o pezinho do bebê.

Essa sequência lógica revela o projeto de texto da criança. Primeiro, há a caracterização do pé ("o pezinho e muinto delicado").

7 Ocorrência de metáfora e metonímia num mesmo dado linguístico. 
Depois, há a orientação para a massagem ("você faz massage no seu pé. Eu faço no meu"). Posteriormente, apresenta-se a informação de que a massagem no pé corresponde à massagem dos órgãos vitais ("[...] também vai está massageando o órgão, o intestino, o estômago"). Em seguida, fala-se das consequências da massagem ("você vai ficar relachado e o seu pezinho vai ficar leve"). Por fim, apresenta-se uma exemplificação como prova de que a massagem faz bem ("o pezinho do bêbê ele vai ficar brincando com o pezinho o dia todo). A elaboração de um projeto de texto coerente deve-se ao fato de que o seu produtor, no contexto de produção, percebe as intenções (TOMASELLO, 1999) do interlocutor. Mais precisamente, a aluna denota compreender que o interlocutor, no caso, a professora, espera receber um texto que faça sentido, que comunique uma ideia. Em O mapa do pezinho, a criança revela a habilidade de compartilhar com o interlocutor a atenção sobre objetos (o pé) e eventos (massagear o pé), além de revelar ter aprendido culturalmente as ações intencionais das pessoas com quem interage, tal como mostra Tomasello (1999) ao falar da "percepção de intenções".

No que diz respeito ao tipo de texto, verifica-se uma mescla de narração, exposição e injunção. A narrativa parece ser a base por meio da qual o texto se construiu. $\mathrm{O}$ ato de narrar, por ser mais básico, está mais próximo da interação do ser aprendente com o mundo. O fato de ter ouvido repetidas vezes histórias contadas pelos adultos (pais, professores, amigos) pode contribuir para que a criança aprenda, na escrita, com a mediação do professor, a distinguir uma história de uma cadeia aleatória de eventos e a produzir um texto coerente. Além disso, conforme Tomasello (1999, p. 158), a perspectiva pela qual a criança elabora a narrativa revela aspectos da cultura em que ela está inserida e o modo de organização da cognição dessa cultura. Em O mapa do pezinho, relaxamento, leveza, saúde corporal e mental são valores culturais conceptualizados como positivos no texto. $O$ texto é também expositivo na medida em que apresenta informações relevantes sobre o tema tratado. Uma dessas informações é que, ao mas- 
Abordagens cognitivistas na aquisição da língua escrita: revisitando O mapa do pezinho Leosmar Aparecido da Silva • Mirian Santos de Cerqueira • André Luiz Rauber

sagear o pé, os órgãos vitais são, por estimulação, massageados. Até mesmo alguma argumentação há no texto quando se fala das vantagens de se massagear o pezinho: ele ficará relaxado e leve. 0 componente injuntivo, apesar de não se manifestar na sua forma prototípica, revela-se quando a criança faz uso da segunda pessoa ("você") genérica em:

1. você faz massage no seu pé.

2. você massageia o seu pezinho.

O uso de "você" no texto soa como uma instrução para o interlocutor realizar a ação descrita. Evidencia-se, assim, a presença de um processo dialógico, interativo, mesmo que não seja síncrono, uma vez que o tempo de produção do texto não é o mesmo tempo de sua leitura pelo interlocutor.

Em relação à organização linguística do texto, padrões abstratos de esquemas oracionais parecem ter sido já adquiridos pela criança. Antes mesmo de internalizar a ortografia de algumas palavras (muinto, massage, relachado), a acentuação (bêbê) ou a separação silábica (massagea-ndo), o padrão esquemático de algumas sentenças parece já estar mais ou menos internalizado. É o caso, por exemplo, dos seguintes padrões:

1. Xé $Y$

O pezinho é muinto delicado.

2. X massageia $Y$

Você massageia o seu pezinho.

Fato interessante é que a autora do texto recorre três vezes a um tipo de estrutura resultativa, fazendo uso da construção " $X$ vai ficar $Y^{\prime \prime}$, como se observa em:

1. você vai ficar relachado. 
2. o seu pezinho vai ficar leve.

3. o pezinho do bêbê ele vai ficar brincando com o pezinho o dia todo.

Em (5) e (6), a criança preenche o "Y" da construção resultativa "X vai ficar Y" com uma forma adjetival ("relachado", "leve"), o que torna essas duas sentenças bastante similares do ponto de vista da forma. Em termos de sentido, ambas as sentenças revelam uma mudança de estado. No contexto da produção, elas funcionam como argumento do enunciador do texto em favor dos benefícios da massagem no pé.

Em (7), porém, apesar de a construção apresentar semelhanças com as duas anteriores, dois aspectos a tornam diferentes.

O primeiro aspecto diz respeito ao uso da estrutura tópica, conhecida como sujeito duplo, em que se faz uso de um sintagma nominal e um pronome ("o pezinho do bêbê ele..."). Em (5) e em (6) não há a presença de estrutura tópica como há em (3). Conforme mencionado na análise gerativista, estudos têm mostrado (PONTES, 1987; BERLINK; AUGUSTO; SCHER, 2001; CANATO; DURÃO, 2005) que a topicalização tem sido cada vez mais usada no português brasileiro falado, muito provavelmente, porque, como houve redução do paradigma flexional, há uma necessidade comunicativa de deixar o sujeito realizado. Como os limites entre oralidade e escrita são tênues e essas duas modalidades constituem, na verdade, um continuum de registros, ora mais formal ora mais informal, a depender do gênero textual, a criança recorreu ao fenômeno da estrutura de tópico como forma de direcionar a atenção do interlocutor para o sintagma topicalizado "o pezinho do bebê".

O segundo aspecto diz respeito ao uso do verbo "brincar" no gerúndio e do adjunto "com o pezinho o dia todo" no lugar de uma forma adjetival. Essa mudança na forma torna a sentença (7) menos resultativa do que (5) e (6). Tal acontece, muito provavelmente, devido ao grau de integração entre os três verbos usados na sentença ("vai"+"ficar"+"brincando"). 
Abordagens cognitivistas na aquisição da língua escrita: revisitando O mapa do pezinho Leosmar Aparecido da Silva • Mirian Santos de Cerqueira • André Luiz Rauber

No texto, as sentenças (5), (6) e (7) ocorrem uma após a outra. Em todas as três, usa-se a perífrase "vai ficar", mas (7), ao mesmo tempo que preserva o padrão, torna-se diferente, o que mostra um dos modos de funcionamento da cognição: os padrões adquiridos podem ser modificados e alterados, conforme a necessidade comunicativa estabelecida pelo uso e consoante a criatividade linguística.

Ainda sobre as construções linguísticas, a criança se vê diante da necessidade de construir cláusulas subordinadas, contudo, tais tipos sentenciais ainda estão em processo de maturação e desenvolvimento. A saída por ela encontrada revelou-se em recorrer aos padrões da coordenação já adquiridos e ao uso de verbos no gerúndio, como em:

1. você massageia o seu pezinho também vai está massageando o órgão, o intestino, o estômago.

A sentença descrita em (8) é complexa uma vez que exige da criança o estabelecimento de uma relação entre dois eventos concomitantes: massagear o pé e massagear o órgão. Num processo avançado de aquisição da escrita, a criança poderia recorrer ao uso de uma cláusula temporal do tipo:

(8a) Ao massagear o seu pezinho, você estará massageando o intestino, o estômago.

Baseando-se, porém, em conhecimentos anteriores, já adquiridos e sedimentados na memória, ela consegue, via criatividade linguística, associar duas sentenças transitivas, utilizando-se da ordem canônica do português [S V O] e do juntivo aditivo "também". Constrói, então, a sentença por meio do seguinte esquema abstrato: "SVO também (S)VO". O resultado é o que se observa no Quadro 1, a seguir: 
Abordagens cognitivistas na aquisição da língua escrita: revisitando 0 mapa do pezinho Leosmar Aparecido da Silva • Mirian Santos de Cerqueira • André Luiz Rauber

Quadro 1 - Estratégia para construção de sentença coordenada

\begin{tabular}{|c|c|c|c|c|c|c|}
\hline $\mathrm{S}$ & $\mathrm{V}$ & $\mathrm{O}$ & TAMBÉM & $\mathrm{S}$ & $\mathrm{V}$ & $\mathrm{O}$ \\
\hline você & massageia & o seu pezinho & também & $\otimes$ & $\begin{array}{c}\text { vai está } \\
\text { massa- } \\
\text { geando }\end{array}$ & $\begin{array}{c}\text { o órgão, o intestino, } \\
\text { o estômago }\end{array}$ \\
\hline
\end{tabular}

Fonte: Elaboração própria

A estratégia utilizada pela criança está de acordo com o que propõe Braggio (1992), na Figura 1, reproduzida anteriormente: contexto da linguagem $\rightarrow$ esquemas mentais $\rightarrow$ utilização de estratégias. O contexto de uso da linguagem exigiu da criança a elaboração de uma hipotaxe adverbial. Como essa estrutura ainda está em desenvolvimento, a criança recorreu aos esquemas mentais já disponíveis em sua memória e modificou-os parcialmente. Tais esquemas direcionaram a utilização da estratégia da coordenação aditiva do tipo "SVO também (S)VO". A ideia de concomitância dos eventos descritos foi estrategicamente construída por meio da perífrase no gerúndio "vai está massageando".

Como se vê, o processo de aquisição da linguagem escrita que procuramos descrever e analisar nesta seção tem semelhança com a aquisição da linguagem oral proposta por Tomasello (1999), uma vez que são considerados processos cognitivos de domínio geral, como "memória rica”, "analogia", "percepção de intenções", "identificação de padrões". A criatividade é um componente da cognição que está sempre presente na manifestação verbal, tanto na produção de metáforas e metonímias quanto na elaboração de alternativas linguísticas variadas para se apresentar uma informação.

Em síntese, ambas as perspectivas teóricas apresentadas no presente artigo assumem a linguagem como uma habilidade/capacidade exclusiva da espécie humana e a predisposição inata para a sua aquisição. Entretanto, divergem em aspectos centrais, tal como a modularidade ou não da cognição humana: os inatistas assumem a linguagem como um sistema de conhecimento autô- 
Abordagens cognitivistas na aquisição da língua escrita: revisitando 0 mapa do pezinho Leosmar Aparecido da Silva • Mirian Santos de Cerqueira • André Luiz Rauber

nomo e os sociocognitivistas assumem a linguagem como um sistema de conhecimento integrado às demais faculdades da mente humana. Este aspecto divergente, em conjunção com os supracitados, culmina no grau diferenciado de relevância que se confere aos aspectos biológicos e socioculturais no processo aquisicional (BEZERRA; SOUZA, 2013).

Do ponto de vista educacional, as contribuições apresentadas pelos dois paradigmas de estudos da linguagem (gerativista e funcionalista), apesar de divergentes em muitos aspectos, podem ser uma ferramenta importante ao professor de língua materna, nas séries iniciais sobretudo, para que possa construir, juntamente com seus alunos, estratégias de aprendizagem focadas no conhecimento linguístico e seu uso nos mais variados contextos comunicativos. Isso, consequentemente, pode colaborar para práticas linguísticas mais autênticas e funcionais, contribuindo para diminuir os déficits de aprendizagem que os estudantes brasileiros apresentam nos mais diferentes níveis de ensino, colaborando, assim, para que se alcance por meio da escrita, patamares de cidadania e adequação linguística nos mais diferentes níveis de uso da linguagem.

\section{Considerações finais}

Este artigo mostrou que, independentemente das divergências quanto ao processo de aquisição da linguagem escrita, as ciências cognitivas ancoradas no gerativismo e no funcionalismo têm muito a contribuir para os estudos sobre a aprendizagem da escrita.

Sob a perspectiva gerativista, os principais aspectos apontados neste estudo e correlacionados ao desenvolvimento da escrita pela criança referem-se: (i) à capacidade combinatorial de itens lexicais de modo a formar sentenças gramaticais; (ii) ao reconhecimento da elipse de constituinte oracional recuperável em parcelas anteriores do texto; e (iii) à evidência da organização tópico e comentário em substituição à estrutura sujeito e predicado. 
Abordagens cognitivistas na aquisição da língua escrita: revisitando 0 mapa do pezinho Leosmar Aparecido da Silva • Mirian Santos de Cerqueira • André Luiz Rauber

Sob a vertente analítica dos Modelos Baseados no Uso, merecem destaque: (iv) o reconhecimento da combinação dos processos cognitivos de domínio geral, principalmente, a memória, a analogia, a percepção de intenções e a recorrência a padrões já adquiridos, para a produção da linguagem escrita; (v) o diálogo entre as linguagens verbal e não verbal para a mescla conceptual; (vi) as marcas que sugerem a compreensão, pelo aprendiz da escrita, das intenções pragmáticas de quem propôs a respectiva atividade.

Somam-se a isto outros condicionamentos. O reconhecimento de que as experiências vividas, o conhecimento enciclopédico armazenado e também tudo que a criança sabe sobre a linguagem escrita são utilizados quando a criança lê ou escreve, é um deles. Sempre que escreve, a criança tenta comunicar algo; inicialmente, ela não se "apega" a letras, sílabas ou palavras isoladas. O aluno procura escrever "em forma de texto, de discurso". Na escrita infantil, o continuum de desenvolvimento parte do não convencional para o convencional. Finalmente, há um ritmo particular de aprendizagem da escrita, dada a necessidade de formular e testar hipóteses.

Os resultados deste trabalho podem contribuir para que profissionais ligados diretamente à educação, especialmente ao ensino de português, possam refletir sobre os aspectos cognitivos e linguísticos implicados nas produções escritas dos alunos.

\section{Referências}

ABREU, A. S. Criatividade: uma visão cognitiva e cultural para o século 21. São Paulo: Giostri, 2020.

AVELAR, J. O. de. O. Saberes Gramaticais: formas, normas e sentidos no espaço escolar. São Paulo: Parábola Editorial, 2017.

BERLINK, R. A.; AUGUSTO, M. R. A.; SCHER, A. P. Sintaxe. In: MUSSALIM, F.; BENTES, A. C. Introdução à linguística: domínios e fronteiras. Vol. 1. 2 ed. São Paulo: Cortez, 2001, p. 207-244. 
Abordagens cognitivistas na aquisição da língua escrita: revisitando O mapa do pezinho Leosmar Aparecido da Silva • Mirian Santos de Cerqueira • André Luiz Rauber

BEZERRA, G. B.; SOUZA, L. B. de. A aquisição da linguagem por Chomsky e por Tomasello. DIcv. João Pessoa, v. 10, n. 1 e 2, jan/dez, p. 19-32, 2013.

BRAGGIO, S. L. B. Leitura e alfabetização: da concepção mecanicista à sociopsicolinguística. Porto Alegre: Artes Médicas, 1992.

BRAGGIO, S. L. B. A importância da construção do sentido na aquisição da linguagem escrita. In: BRAGGIO, S. L. B. Contribuições da linguística para a alfabetização. Goiânia: Editora UFG, 1995, p. 125-139.

BRAGGIO, S. L. B. Contribuições da linguística para o ensino de línguas. Goiânia: CEGRAF-UFG, 1999.

BYBEE, J. Language, usage and cognition. Cambridge: Cambridge University Press, 2010.

CANATO, A. P. M. B.; DURÃO, A. B. de A. B. O duplo sujeito gramatical em produções de brasileiros aprendizes de inglês: influência evidente da língua materna. Revista do Gel. Campinas-SP, v. 2, p. 107-117, 2005. CERQUEIRA, M. S. de; SILVA, L. A. Colocação pronominal e ensino de português: possibilidades metodológicas para a educação básica. Scripta, Belo Horizonte, v. 25, n. 53, p. 618-651, 2021.

CHOMSKY, N. Syntactic Structures. The Hague: Mouton, 1957.

CHOMSKY, N. Reviews: verbal behavior. By B. F. Skinner reviewed by Noam Chomsky. Massachusetts Institute of Technology and Institute for Advanced Study, 1959. Language, v. 35.

CHOMSKY, N. O Conhecimento da Língua: Sua Natureza, Origem e Uso. Lisboa: Editora Caminho, 1994 [Original 1986].

CROFT, W.; CRUSE, A. Cognitive linguistics. Cambridge: Cambridge University Press, 2004.

DIK, S. C. The theory of functional grammar. Part 1: The structure of the clause. Kees Hengeveld (Ed.). New York: Mounton de Gruyter, 1997.

FRANCHI, C. Criatividade e gramática. Trabalhos em linguística aplicada, São Paulo, v. 9, n. 1, 1987. p. 5-45.

GERALDI, J. W. Portos de passagem. 4 ed. São Paulo: Martins Fontes, 1997. 
Abordagens cognitivistas na aquisição da língua escrita: revisitando O mapa do pezinho Leosmar Aparecido da Silva • Mirian Santos de Cerqueira • André Luiz Rauber

KATO, Mary. No mundo da escrita: uma perspectiva psicolinguística. São Paulo: Ática, 1986.

KATO, M. A. Aquisição da linguagem numa abordagem gerativa. Letras de Hoje, Porto Alegre. v. 34, n. 3, p. 17-25, setembro de 1999.

KATO, M. A. A gramática do letrado: questões para a teoria gramatical. In: MARQUES, M A.; J. T. KOLLER; A. S. LEMOS (orgs.). Ciências da linguagem: trinta anos de investigação e ensino, Braga - CEHUM (Universidade do Minho), 2005. p. 131-145.

KENEDY, E. Possíveis contribuições da Linguística Gerativa à formação do professor de Língua Portuguesa. Rev. de Letras, Fortaleza, v. 1, n. 32, - jan./jun. p. 72-79. 2013.

LANGACKER, R. W. Foundations of Cognitive Grammar. Vol 1. Theoretical prerequisites. Stanford, Cal.: Sanford University Press, 1987. LANGACKER, R. W. Essentials of cognitive grammar. New York: Oxford University Press, 2013.

LOPES, R. V. Uma proposta minimalista para o processo de aquisição da linguagem: relações locais. 1999. Tese (Doutorado em Linguística) - Instituto de Estudos da Linguagem, Unicamp: Campinas, SP, 1999.

MAGALHÃES, T.M.V. Aprendendo o sujeito nulo na escola. 2000. Dissertação (Mestrado em Linguística) - Instituto de Estudos da Linguagem, Unicamp: Campinas, SP, 2000.

PIAGET, J. Le langage et la pensée chez l'enfant. 1923. In: VIGOTSKY, L. S. Pensamento e linguagem. Trad. Jefferson Luiz Camargo. 2. ed. São Paulo: Martins Fontes, 2000. p. 19-96.

PONTES, E. O tópico do Português do Brasil. Campinas: Pontes Editores, 1987.

RAUBER, A. L. Aquisição da escrita: a construção textual em “O mapa do pezinho". Revista Temporis[ação], Cidade de Goiás, v. 9. n. 1. 2008. p. 103-113.

SKINNER, B. F. Verbal behavior. Englewood Cliffs, NJ: Prentice-Hall, 1957. 
Abordagens cognitivistas na aquisição da língua escrita: revisitando 0 mapa do pezinho Leosmar Aparecido da Silva • Mirian Santos de Cerqueira • André Luiz Rauber

SILVA, A. C. Descobrir o princípio alfabético. Anais... Psicologia, Lisboa, v. 22, n. 1, p. 187-191, março/2004. Disponível em: http://www.scielo.mec.pt/scielo.php?script=sci_arttext\&pi$d=$ S0870-82312004000100017\&lng=es\&nrm=iso. Acesso em: 16 fev. 2021.

TOMASELLO, M. Origens culturais do conhecimento humano. Trad. Cláudia Berliner. São Paulo: Martins Fontes, 2003.

TOMASELLO, M. Linguistic Constructions and Event Cognition In: TOMASELLO, M. The cultural origins of Human Cognition. Harvard University Press, Cambridge, Mass, 1999. p. 134-160.

VIGOTSKY, L. S. Pensamento e linguagem. Trad. Jefferson Luiz Camargo. 2. ed. São Paulo: Martins Fontes, 1998. 